\title{
New bis(azobenzocrown)s with dodecylmethylmalonyl linkers as ionophores for sodium selective potentiometric sensors
}

\author{
Elżbieta Luboch $^{1} \cdot$ Maciej Jeszke ${ }^{1} \cdot$ Mirosław Szarmach $^{1} \cdot$ Natalia Lukasik $^{1}$
}

Received: 14 June 2016/Accepted: 17 September 2016/Published online: 29 September 2016

(c) The Author(s) 2016. This article is published with open access at Springerlink.com

\begin{abstract}
Novel biscrowns 1 and $\mathbf{2}$ were synthesized from 13-membered azobenzocrown ethers containing bromoalkylenoxy chains in para position relative to the azo group. The synthesized diester molecules are dodecylmethylmalonic acid derivatives differing by the linker length. The synthesized compounds have the potential of being used as sodium ionophores in ion-selective electrodes. They were characterized and used as ionophores in classic and miniature, solid contact (screen-printed and glassy carbon) membrane ion-selective electrodes. Compound $\mathbf{3}$, a similar monoester derivative of 13 -membered azobenzocrown, was synthesized and used in membrane electrodes for comparison. Lipophilicity of new ionophores was determined by TLC. Lipophilicity of bis(azobenzocrown)s was found to be within the range of $\log \mathrm{P}_{\mathrm{TLC}}=12-13$. It was observed that the particularly important selectivity coefficients $\log K_{N a, K}$ determined for new electrodes, being $\log K_{\mathrm{Na}, \mathrm{K}}=-2.5$ and -2.6 (SSM, $0.1 \mathrm{M}$ ), are better than those of the electrodes featuring seven out of the nine commercially available sodium ionophores. It was concluded that the ionophore $\mathbf{1}$ creates, in acetone, with sodium iodide, complex of 1:1 stoichiometry (sandwich complex) with stability constant $(\log K)$ ca. 3.0.
\end{abstract}

Keywords Bis(azobenzocrown)s · Synthesis · Sodium ionophores · Ion-selective electrodes · Solid contact electrodes

Elżbieta Luboch

elzbieta.luboch@pg.gda.pl

1 Department of Chemistry and Technology of Functional Materials, Faculty of Chemistry, Gdańsk University of Technology, Narutowicza 11/12, 80-233 Gdańsk, Poland

\section{Introduction}

Molecular receptors based on macrocyclic compounds are established as complexation agents for metal cations. An interesting group of alkali metal complexation compounds consists the crown ethers incorporating azobenzene moieties as part of the macrocycle, i.e. azobenzocrown ethers. Numerous macrocyclic compounds with inherent 2,2'azobenzene moieties were synthesized and studied exhaustively [1-4]. Broad possibilities for functionalization of azobenzocrowns result in their potential applications in a variety of fields, e.g. lipophilic crowns may be successfully used as ionophores, both in classic and miniature solid contact ion-selective membrane electrodes (ISEs) [2-4].

Azobenzocrowns with peripheral hydroxyl groups are compounds with chromoionophoric and fluoroionophoric properties [5-7]. At the same time, they are convenient substrates for further modifications of azobenzocrowns and allow introduction of various peripheral functional groups including derivatives featuring reactive bromine atoms within the side chains [8]. Chromoionophoric properties are also observed e.g. for azobenzocrowns featuring amine substituents within the benzene ring and pull-push type azobenzocrowns featuring nitro and dimethylamine groups within the benzene rings $[2,9]$.

In our earlier studies we have found that ISEs with 13-membered azobenzocrown ionophores in membranes are sodium selective. We obtained and used in the membrane ion-selective electrodes a number of 13-membered azobenzocrowns with modifications within the benzene rings, including crowns with: hydrocarbon moieties, hydrocarbon moieties linked by an ether group, compounds with ester or amide groups within the side chains or bis(azobenzocrown)s with two azobenzocrowns connected via an $\alpha, \omega$-dioxaalkane [2-4]. 
Most typically, ISEs based on crown ethers ionophores are selective towards ions (including sodium cations) that form sandwich-type complexes with crown ethers [10-12] (the exception being crown ethers that contain blocking subunits disallowing formation of complexes with cations larger than the macrocycle gap, e.g. [13]). It was previously reported that the 13-membered azobenzocrowns form crystalline sandwich-type complexes (2:1, crown:cation) with sodium ions, with the complexed cations being wellseparated from the anions [12]. Macrocycles of this ring size have complexing properties similar to those of 12-crown-4 [14]. Conditions for the formation of sandwich-type complexes may be favored when two macrocycles are appropriately linked to form bis(crown ether)s. Due to cooperation of the neighboring crown units, biscrown derivatives tend to form stronger complexes with the particular ions than their respective monocrowns [15]. The linker binding the two crown units has a significant effect on the formation of sandwich complexes by biscrown ethers [16]. Both the length and the flexibility of the linker are of importance e.g. [17]. Intramolecular sandwich complexes cannot be formed in case of rigid molecules where the crowns lie either too far apart or too close to each other. However, intermolecular complexes may be formed instead. In particular cases, a 2:2 (biscrown:ion) stoichiometry is possible, with two cations being shared by two ligand molecules [18, 19]. Such is the case, for example, in bis(azobenzocrown) with a short, dioxyethylene linker that forms an intermolecular sandwich-type complex of 2:2 stoichiometry with sodium ions [3].

Recently, much attention was focused on the use of ISEs for clinical analysis [20]. The sensors, forming part of commercial analyzers, are applied for the measurement of ions such as sodium, potassium, calcium, magnesium, lithium, ammonium, hydrogen, chloride, and bicarbonate. Ionophores for use in ISEs applied for determination of all these ions are available commercially. One to nine ionophores are offered for each ion [21]. However, the literature contains reports regarding much higher numbers of ionophores, sometimes including some that seem more interesting but have not been commercialized for various reasons eg. [22]. For example, the sensational ISEs featuring calix[4]crown-4, selective towards sodium ions, absorb proteins which prevents them from being used in measurements carried out in blood or cell cultures [23]. As observed in an example of azobenzocrowns, different from those reported herein, azobenzocrowns with no structural similarity to natural compounds have no affinity towards protein molecules [24].

High selectivities, e.g. for sodium-selective electrodes, particularly in the case of calix[4]arene ionophores application, are obtained when the ISE did not have any contact with the primary ion before the measurement. However, usually the again used sodium-selective electrode shows even two orders of magnitude worse sodium/potassium selectivity coefficient $[13,25]$.

We are interested in the search for new, interesting ionophores for electrodes to be used for clinical analytics, including sodium electrodes. Although commercial sodium ionophores are quite numerous when compared to other ionophores, not many highly lipophilic compounds characterized by very good sodium/potassium selectivity are available [21]. Lack of interference with calcium and magnesium ions is also important from the clinical analytics point of view.

Table 1 presents the properties of sodium-selective membrane electrodes suitable for clinical analytics in terms of both selectivity and lipophilicity [26].

Among the nine commercially available sodium ionophores (Fluka, Sigma-Aldrich) can be distinguished: podands (diamides and triamides), crown ethers (including biscrowns), an ester derivative of calixarene and monensin methyl ester [21].

In Fig. 1 the most important sodium ionophores are shown representing four groups of compounds: acyclic triamides, crown ethers, biscrowns, and derivatives of calix[4]arene.

In the case of amide-based podands, e.g. sodium ionophore I different selectivity $\log K_{\mathrm{Na}, \mathrm{K}}$ ranging from -0.2 was obtained depending on ISE type and measurement conditions [21]. A satisfactory value of selectivity coefficient for potassium can be also gained, e.g. I (SSM $0.1 \mathrm{M}$, $o$-NPOE, $\mathrm{TPB}^{-}$): $\log K_{\mathrm{Na}, \mathrm{K}}=-2.3$, however not good enough discrimination of lithium and calcium ions may be a problem $\left(\log K_{\mathrm{Na}, \mathrm{Li}}=0.4 ; \log K_{\mathrm{Na}, \mathrm{Ca}}=0.2\right)$ [27]. By changing a plasticizer the improvement of calcium selectivity can be achieved (I, BBPA (SSM): $\log K_{\mathrm{Na}, \mathrm{K}}=-2.0$; $\left.\log K_{\mathrm{Na}, \mathrm{Li}}=0.5 ; \log K_{\mathrm{Na}, \mathrm{Ca}}=-1.5\right)$ [28].

High discrimination of potassium ions can be obtained by introduction to 16 -crown-5 ring of two bulky decaline units to prevent the formation of 2:1 complexes by the crown with potassium ions (ionophore IV, BBPA + TEHP (FIM): $\quad \log \quad K_{\mathrm{Na}, \mathrm{K}}=-3.0 ; \quad \log \quad K_{\mathrm{Na}, \mathrm{Li}}=-3.1 ; \quad \log$

Table 1 ISE selectivities required for determination of sodium ions in clinical analytics and minimum recommended lipophilicity of the ionophore [26]

\begin{tabular}{ll}
\hline $\begin{array}{l}\text { Required ISE selectivity } \\
\text { in plasma } \\
\text { and ionophore lipophilicity }\end{array}$ & $\begin{array}{l}\text { Required ISE selectivity } \\
\text { in urine } \\
\text { and ionophore lipophilicity }\end{array}$ \\
\hline $\log K_{\mathrm{Na} / \mathrm{K}}<-0,6$ & $\log K_{\mathrm{Na} / \mathrm{K}}<-2,1$ \\
$\log K_{\mathrm{Na} / \mathrm{Ca}}<-1,3$ & $\log K_{\mathrm{Na} / \mathrm{Ca}}<-0,6$ \\
$\log K_{\mathrm{Na} / \mathrm{Mg}}<-1,2$ & $\log K_{\mathrm{Na} / \mathrm{Mg}}<-0,6$ \\
$\log K_{\mathrm{Na}, \mathrm{H}}<4.4$ & $\log K_{\mathrm{Na}, \mathrm{H}}<1.4$ \\
$\log \mathrm{P}_{\mathrm{TLC}}>8.4$ & $\log \mathrm{P}_{\mathrm{TLC}}>2.3$ \\
\hline
\end{tabular}




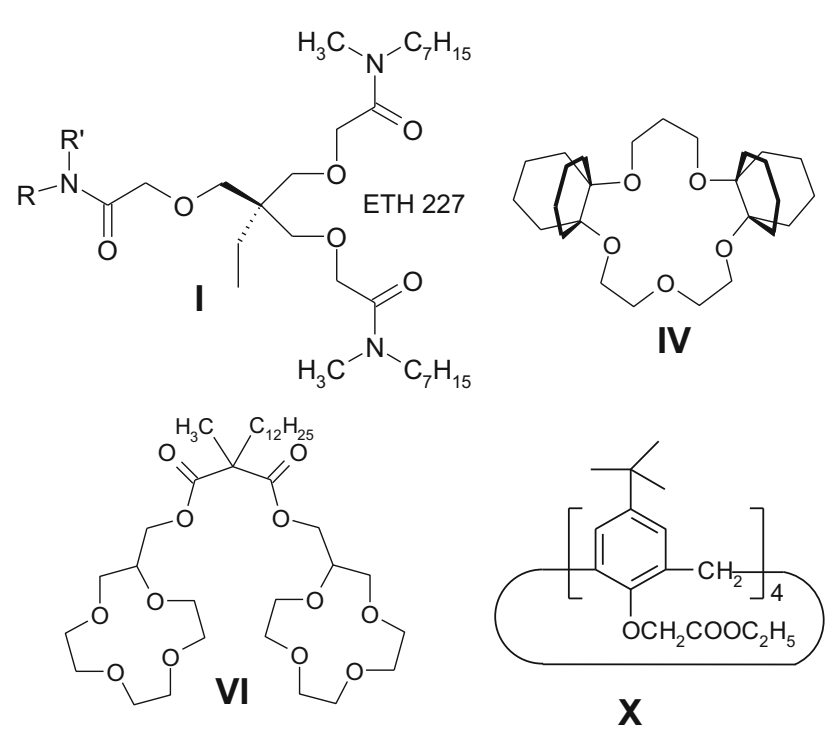

Fig. 1 Commercial sodium ionophores: I, IV, VI and $\mathbf{X}$ (ionophore symbols by Fluka)

$\left.K_{\mathrm{Na}, \mathrm{Ca}}=-4.0\right)$ [13]. A disadvantage of this ionophore is its high price.

Relatively high discrimination of potassium and lithium ions can be achieved by using of biscrown ionophores with two 12-crown-4 units, that create sandwich complexes with sodium ions (e.g. ionophore VI (MSM, o-NPOE): $\log$ $K_{\mathrm{Na}, \mathrm{K}}=-2.0 ; \log K_{\mathrm{Na}, \mathrm{Li}}=-3.0 ; \log K_{\mathrm{Na}, \mathrm{Ca}}=-4.0 ; \log$ $\left.K_{\mathrm{Na}, \mathrm{Mg}}=-4.0\right)$ [14]. Sodium ionophores from the biscrown group usually discriminate calcium and magnesium ions strongly.

The unquestionable leader of the ionophore sodium is currently ionophore $\mathbf{X}-p$-tert-butylcalix[4]arene-tetraacetic acid tetraethyl ester, one of many derivatives of calix[4]arene (ester- and amide-based), selective for sodium ions which have been described in literature eg. [22]. The ionophore $\mathbf{X}$, much cheaper than ionophore $\mathbf{I V}$, characterized in a little bit poorer selectivity for potassium ions (e.g. $\mathbf{X}$ (SSM, $o$-NPOE): $\log K_{\mathrm{Na}, \mathrm{K}}=-2.7 ; \log$ $K_{\mathrm{Na}, \mathrm{Li}}=-3.4$ [29]) is commonly used in most studies of the potentiometric sodium ions determination.

Recent researches, where among the others sodium-selective ionophores are used, are focused more on new technical solutions and new areas of sensor systems application than on search for novel, selective ionophores, e.g. [30-34].

Now, new diester bis(azobenzocrown)s, derivatives of dodecylmethylmalonic acid, were synthesized, being somewhat analogous to the known, commercially available sodium ionophore VI [35]. The new compounds 1 and $\mathbf{2}$ (Scheme 1), as well as the new monoester derivative $\mathbf{3}$ acting as the comparative ionophore, were used in classic membrane ion-selective electrodes and miniature electrodes of the solid contact type: glassy carbon and graphite screen-printed. As the ionophores are photoactive compounds having ability to isomerization, the influence of light in UV range on obtained electrodes properties as well as the presence of sodium ions on isomerization of tested bis(azobenzocrown)s was examined. The stoichiometry of complex of bis(azobenzocrown) 1 with sodium ions was determined.

\section{Experimental}

\section{General}

Materials (mainly from Sigma-Aldrich) and solvents (mainly from POCH, Poland) for synthesis were of analytical reagent grade and used without further purification. Silica gel $60(0.063-0.200 \mathrm{~mm})$ (Merck) was used for column chromatography. TLC: silica gel $60 \mathrm{~F}_{254}$-coated aluminum sheets were purchased from Merck. TLC determination of lipophilicity was conducted using RP-18 F254S, $0.25 \mathrm{~mm}$ plates (Merck) and bis(2-ethylhexyl)sebacate (DOS), bis(2ethylhexyl)phthalate (DOP), bis(1-butylpentyl)adipate (BBPA) and $o$-nitrophenyl octyl ether (o-NPOE) (SigmaAldrich) as plasticizer references. Tetrahydrofuran (THF) for membrane preparation was freshly distilled over $\mathrm{LiAlH}_{4}$. For the preparation of polymeric ion-selective membranes, poly(vinyl chloride) (PVC, high molecular weight), potassium tetrakis(4-chlorophenyl)borate (KT $p$ ClPB), poly(sodium 4-styrenesulfonate) (NaPSS), ethylenedioxythiophene (EDOT), poly(3,4-ethylenedioxythiophene)/poly (styrenesulfonate) blend (PEDOT/PSS, used as $1.3 \%(\mathrm{w} / \mathrm{w})$ dispersion in water (conductive grade)), p-tert-butylcalix[4]arene-tetraacetic acid tetraethyl ester (Sodium Ionophore $\mathbf{X})$ and bis[(12-crown-4)methyl]dodecylmethylmalonate (Sodium Ionophore VI) were used as received from Sigma-Aldrich.

The screen-printed graphite electrodes were prepared in the Institute of Electronic Materials Technology, Warsaw (plates of 18-15 mm with six electrodes, opening areas of ca. $1 \mathrm{~mm}^{2}$, substrate-polyester film, $125 \mu \mathrm{m}$ thick, type CT-5 (Autostat), dielectric paste type 5018 (Du Pont, UVcured). Carbon nanotubes (Thin MWCNT 95\%) were obtained from Nanocyl S.A., Belgium.

Glassy carbon electrodes (glassy carbon disk of $1.8 \mathrm{~mm}$ in diameter in poly(ether ether ketone) casing were obtained from Mineral ${ }^{\circledR}$ (Warsaw, Poland).

The aqueous solutions were prepared with deionized water of conductivity below $0.1 \mu \mathrm{S} / \mathrm{cm}$, obtained using a Hydro-Lab-PL reverse osmosis (RO) station.

${ }^{1} \mathrm{H}$ NMR spectra were recorded on a Varian instruments at $500 \mathrm{MHz}$. Mass spectra were recorded on a SYNAPT G2-S HDMS (Waters) (ESI) spectrometer. FTIR spectra were recorded using a Mattson Genesis II instrument. UV- 


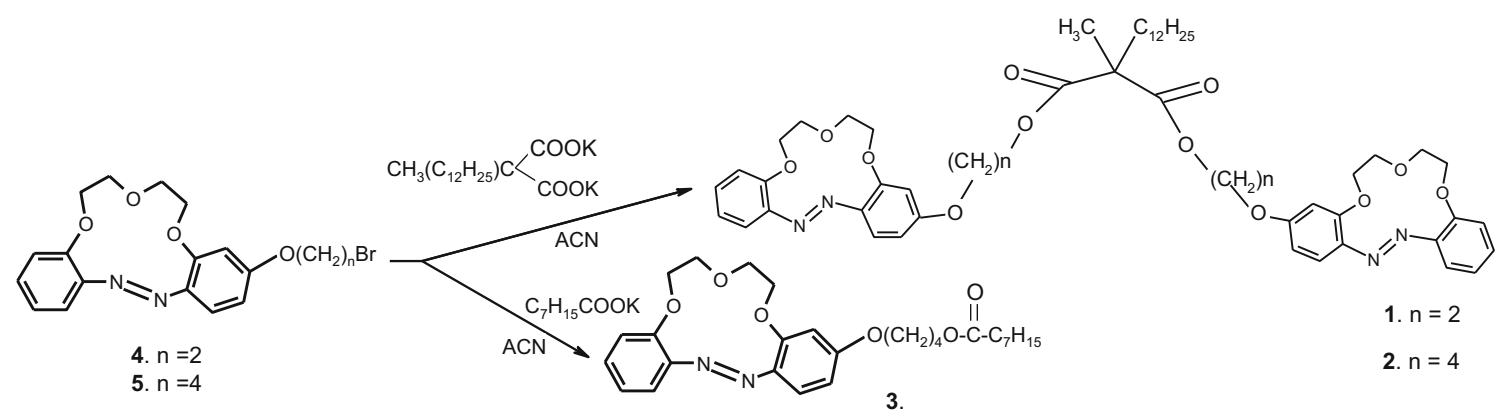

Scheme 1 Method of synthesis and structures of the new ionophores tested in sodium selective membrane electrodes

Vis spectra were recorded using a UNICAM UV 300 apparatus. All EMF was measured with 16-channel potentiometer (Lawson Labs. Inc., USA) connected to a computer with EMF Suite data logging software version 2.0. $\mathrm{pH}$ was monitored using a $\mathrm{pH}$-meter $\mathrm{CX}-505$ and electrode EPP-1 (ELMETRON).

\section{Synthesis}

The ionophores were prepared as shown in the Scheme 1.

Potassium dodecylmethylmalonate $(54.3 \mathrm{mg}$, $0.15 \mathrm{mmol}$ ), the bromo derivative 4 or 5 [8] (122 or $130 \mathrm{mg}, 0.30 \mathrm{mmol}$ ) and a catalytic amount of 18-crown-6 in dry acetonitrile $(5 \mathrm{ml})$ were heated at $75{ }^{\circ} \mathrm{C}$ for $24 \mathrm{~h}$. Then, the solvent was evaporated under reduced pressure and the residue was separated by column chromatography on silica gel. Compounds $\mathbf{1}$ and $\mathbf{2}$ may theoretically occur as three stereoisomers, two of which were mainly present in solutions containing the product. One of the isomers was eluted from the column with a mixture of chloroform:acetone 5:1 and the other with a mixture of chloroform:methanol 5:1. After comparison of chromatograms of individual fractions (TLC) (after about $1 \mathrm{~h}$ ), fractions containing stereoisomers of individual compounds were combined and solvents were evaporated under reduced pressure. Oily residues were crystallized from ethyl acetate:hexane mixture. Compound $\mathbf{1}$ (red-orange solid) was obtained in a $38 \%$ yield, mp $84-87^{\circ} \mathrm{C}$. Compound 2 (red-orange solid) was obtained in a $43 \%$ yield, mp $57-58{ }^{\circ} \mathrm{C}$ (mainly trans-trans isomer).

Compound 1 was treated with an equimolar amount of sodium iodide dissolved in methanol. The resulting mixture was evaporated under reduced pressure and, after several hours, subjected to ${ }^{1} \mathrm{H}$ NMR analysis in d-acetone.

Compound 1. TLC: $\mathrm{R}_{\mathrm{f}}=0.20,0.33$ and 0.51 for transtrans, trans-cis and cis-cis isomers respectively (dichloromethane:acetone, 4:1, v/v); $\mathrm{R}_{\mathrm{f}}=0.31,0.76$ and 0.81 for trans-trans, trans-cis and cis-cis isomers respectively (chloroform:methanol, 10:1, v/v). ${ }^{1} \mathrm{H}$ NMR (dacetone), mixture of isomers: $0.84-0.90(3 \mathrm{H}, \mathrm{m}) ; 1.20-1.32$
$(20 \mathrm{H}, \mathrm{m}) ; 1.38-1.44(3 \mathrm{H}, \mathrm{m}) ; 1.80-1.92(2 \mathrm{H}, \mathrm{m}) ; 3.60$ $(\sim 1.3 \mathrm{H}, \mathrm{s}) ; 3.86-4.60(\sim 22.7 \mathrm{H}, \mathrm{m}) ; 6.30-7.80(14 \mathrm{H}, \mathrm{m})$. FT-IR (film): $\mathrm{C}=\mathrm{O} 1733 \mathrm{~cm}^{-1}$. UV-Vis (acetone): $\lambda(\varepsilon)=361 \mathrm{~nm}\left(2.3 \times 10^{4}\right) ; 437 \mathrm{~nm}\left(2.7 \times 10^{3}\right)$. HRMS (ESI): $[\mathrm{M}+\mathrm{Na}]^{+} 961.4570$ calculated for $\mathrm{C}_{52} \mathrm{H}_{66} \mathrm{~N}_{4} \mathrm{O}_{12} \mathrm{Na}$ 961.4575.

Compound 1-NaI. ${ }^{1} \mathrm{H}$ NMR (d-acetone), signals for trans-trans isomer (ca. $90 \%$ of content): $0.85-0.90(3 \mathrm{H}$, $\mathrm{m}) ; 1.22-1.39(20 \mathrm{H}, \mathrm{m}) ; 1.46(3 \mathrm{H}, \mathrm{s}) ; 1.91-1.94(2 \mathrm{H}, \mathrm{m})$; 3.94-4.05 (8H, m); 4.21-4.40 (12H, m); $4.51(4 \mathrm{H}, \mathrm{t}$, $J=5 \mathrm{~Hz}) ; 6.67-6.72(4 \mathrm{H}, \mathrm{m}) ; 7.01(2 \mathrm{H}, \mathrm{d}, J=8 \mathrm{~Hz})$; $7.07(2 \mathrm{H}, \mathrm{t}, J=8 \mathrm{~Hz}) ; 7.23(2 \mathrm{H}, \mathrm{t}, J=7 \mathrm{~Hz}) ; 7.34(2 \mathrm{H}, \mathrm{d}$, $J=8 \mathrm{~Hz}) ; 7.38(2 \mathrm{H}, \mathrm{d}, J=9 \mathrm{~Hz})$.

Compound 2. TLC: $\mathrm{R}_{\mathrm{f}}=0.04,0.48$ and 0.57 for transtrans, trans-cis and cis-cis isomers respectively (dichloromethane:acetone, 4:1, v/v); $\mathrm{R}_{\mathrm{f}}=0.18,0.82$ and 0.87 for trans-trans, trans-cis and cis-cis isomers respectively (chloroform:methanol, 10:1, v/v). ${ }^{1} \mathrm{H}$ NMR (dacetone), signals for trans-trans isomer: $0.84-0.88(3 \mathrm{H}$, m); $1.27-1.39(20 \mathrm{H}, \mathrm{m}) ; 1.41(3 \mathrm{H}, \mathrm{s}) ; 1.87-1.92(10 \mathrm{H}, \mathrm{m})$; $3.86-3.94(8 \mathrm{H}, \mathrm{m}), 4.12(4 \mathrm{H}, \mathrm{t}, J=6 \mathrm{~Hz}) ; 4.21-4.29$ $(12 \mathrm{H}, \mathrm{m}) ; 6.71(2 \mathrm{H}, \mathrm{d}, J=1 \mathrm{~Hz}) ; 6.74(2 \mathrm{H}, \mathrm{d}, J=2 \mathrm{~Hz})$; $7.13-7.18(4 \mathrm{H}, \mathrm{m}) ; 7.35(2 \mathrm{H}, \mathrm{t}, J=7 \mathrm{~Hz}) ; 7.65(2 \mathrm{H}, \mathrm{d}$, $J=8 \mathrm{~Hz}) ; 7.73(2 \mathrm{H}, \mathrm{d}, J=9 \mathrm{~Hz})$. FT-IR (film): C $=\mathrm{O}$ $1730 \mathrm{~cm}^{-1}$. HRMS (ESI): $[\mathrm{M}+\mathrm{Na}]^{+} 1017.5187$ calculated for $\mathrm{C}_{56} \mathrm{H}_{74} \mathrm{~N}_{4} \mathrm{O}_{12} \mathrm{Na}$ 1017.5201.

Compound 3 was synthesized in an analogous manner using potassium octoate $(54.6 \mathrm{mg}, 0.30 \mathrm{mmol})$. The product was eluted from the column with methylene chloride:acetone 5:1 and then crystallized in mass. Yield $64 \%$, mp $47-49{ }^{\circ} \mathrm{C}$ (red solid). TLC: $\mathrm{R}_{\mathrm{f}}=0.50$ and 0.77 for trans and cis isomers respectively (dichloromethane: acetone, $4: 1, \mathrm{v} / \mathrm{v}) ; \mathrm{R}_{\mathrm{f}}=0.76$ and 0.85 for trans and cis isomers respectively (chloroform:methanol, 10:1, v/v).

${ }^{1} \mathrm{H}$ NMR (d-acetone), mixture of trans and cis isomers (3:2): $0.88 \quad(3 \mathrm{H}, \quad \mathrm{t}, \quad J=7 \mathrm{~Hz}) ; \quad 1.24-1.36 \quad(8 \mathrm{H}, \quad \mathrm{m})$; 1.55-1.64 (2H, m); 1.75-1.94 (4H, m); 2.27-2.34 (2H, m); $3.87-4.32(12 \mathrm{H}, \quad \mathrm{m}) ; \quad 6.30 \quad\left(0.4 \mathrm{H}, \quad \mathrm{dd}, \quad J_{1}=9 \mathrm{~Hz}\right.$, $\left.J_{2}=2 \mathrm{~Hz}\right) ; 6.51(0.4 \mathrm{H}, \mathrm{d}, J=9 \mathrm{~Hz}) ; 6.58(0.4 \mathrm{H}, \mathrm{d}$, $J=2 \mathrm{~Hz}) ; 6.75-6.78(1.2 \mathrm{H}, \mathrm{m}) ; 6.83-6.88(0.8 \mathrm{H}, \mathrm{m}) ; 6.94$ 
$(0.4 \mathrm{H}, \quad \mathrm{d}, \quad J=8 \mathrm{~Hz}) ; \quad 7.10 \quad\left(0.4 \mathrm{H}, \quad \mathrm{dd}, \quad J_{1}=8 \mathrm{~Hz}\right.$, $\left.J_{2}=2 \mathrm{~Hz}\right) ; 7.16(0.6 \mathrm{H}, \mathrm{t}, J=8 \mathrm{~Hz}) ; 7.20(0.6 \mathrm{H}, \mathrm{d}$, $J=8 \mathrm{~Hz}) ; 7.37(0.6 \mathrm{H}, \mathrm{t}, \quad J=8 \mathrm{~Hz}) ; 7.69(0.6 \mathrm{H}, \mathrm{d}$, $J=8 \mathrm{~Hz}) ; 7.78(0.6 \mathrm{H}, \mathrm{d}, J=10 \mathrm{~Hz})$. FT-IR (film): $\mathrm{C}=\mathrm{O} 1732 \mathrm{~cm}^{-1}$. HRMS (ESI): $[\mathrm{M}+\mathrm{H}]^{+}$499.2798, calculated for $\mathrm{C}_{28} \mathrm{H}_{39} \mathrm{~N}_{2} \mathrm{O}_{6} 499.2808$.

\section{Ion selective electrodes membrane preparations and EMF measurements}

Membranes containing the ionophores $\mathbf{1}, \mathbf{2}$ or $\mathbf{3}(6 \mathrm{mg}$, $3.8 \%(\mathrm{w} / \mathrm{w}))$, PVC (50 mg, $31.8 \mathrm{wt} \%), o$-NPOE (100 mg, $63.7 \%(\mathrm{w} / \mathrm{w}))$ and $\mathrm{KT} p \operatorname{ClPB}(1.1 \mathrm{mg}, 0.7 \%(\mathrm{w} / \mathrm{w}))$ were prepared for classical electrodes (c). All components were dissolved in $1.2 \mathrm{~mL}$ of freshly distilled THF and transferred to a glass ring (15 $\mathrm{mm}$ i.d.). The solvent was allowed to evaporate overnight at ambient temperature. From obtained membrane discs (7 mm dia.) were cut out and mounted onto Philips electrode bodies (W. Moller AG, Zurich). Next, the membrane electrodes were soaked in $10^{-2} \mathrm{M} \mathrm{NaCl}$ overnight prior to use. Philips silver chloride electrode (W. Moller AG, Zurich) was used as the reference electrode in the measurements. Potentials were measured using the following galvanic cell: $\mathrm{Ag}$ I $\mathrm{AgCl}(\mathrm{s})|\mathrm{KCl}(1 \mathrm{M})| \mathrm{CH}_{3} \mathrm{COOLi}(1 \mathrm{M}) \mid$ sample solution | ion-selective membrane $\left|\mathrm{NaCl}\left(10^{-2} \mathrm{M}\right)\right| \mathrm{AgCl}(\mathrm{s}) \mid \mathrm{Ag}$.

For screen-printed electrodes (s-p) the membranes of analogous composition as for classical electrodes were prepared. Carbon nanotubes were optionally added to membrane to be deposited on graphite screen-printed electrodes (s-p,n). Carbon nanotubes $(0.05 \mathrm{mg})$ in $1.2 \mathrm{~mL}$ THF were sonicated for $15 \mathrm{~min}$. Next, the remaining components were added in quantities typical for classic electrodes. The resulting cocktail $(1 \mu \mathrm{L})$ was dosed onto graphite screen-printed electrodes (membrane surface area of ca. $1.5 \mathrm{~mm}^{2}$ ). After $5 \mathrm{~min}$, another, identical portion of the cocktail was applied. The electrodes were left for solvent evaporation over at least $6 \mathrm{~h}$ at ambient temperature. Next, the electrodes were soaked in $10^{-3} \mathrm{M} \mathrm{NaCl}$ for $10 \mathrm{~h}$ prior to use. The same reference electrode was used as in the case of classic electrodes.

The conductive polymer layer (PEDOT/PSS, $5 \mu \mathrm{L}$ ) was transferred onto glassy carbon electrodes gc (application area: disc $1.8 \mathrm{~mm}$ in dia.). The electrodes were left for $24 \mathrm{~h}$ at room temperature before the deposition of the membrane $(15 \mu \mathrm{L})$ onto an area of ca. $4 \mathrm{~mm}$ in diameter. After $5 \mathrm{~min}$, another, identical portion of the cocktail was applied. Electrodes were left overnight at ambient temperature. Later, the membrane electrodes were soaked in $10^{-3} \mathrm{M}$ $\mathrm{NaCl}$ overnight. The composition of membranes was analogous as for classical electrodes, but here also DOS instead of $o$-NPOE was used (in the same quantity).
Composition of the membranes containing the reference calixarene tetraester (Sodium Ionophore $\mathbf{X}$, SI-X) was as follows: ionophore (2 mg, $1.3 \%$ (w/w)), PVC (49.5 mg, $32.8 \%(\mathrm{w} / \mathrm{w})), o-\operatorname{NPOE}(99.2 \mathrm{mg}, 65.7 \%(\mathrm{w} / \mathrm{w}))$, and KTpCIPB (0.3 mg, $0.2 \%$ (w/w)).

Composition of the membranes containing the reference bis[(12-crown-4)methyl]dodecylmethylmalonate (Sodium Ionophore VI, SI-VI) was as follows: ionophore $(5.2 \mathrm{mg}$, $6.5 \%$ (w/w)), PVC (21.44 mg, $26.8 \%$ (w/w)), $o$-NPOE (53.36 mg, $66.7 \%(\mathrm{w} / \mathrm{w}))$.

Alternatively, for one, comparative series of electrodes $\left(\mathbf{g c}^{\prime}\right)$ with ionophore $\mathbf{1}$ the conductive polymer was introduced by electropolymerization. Films consisting electroactive polymer were prepared by direct electropolymerization on the glassy carbon electrodes from the suspension (in electrolyte) containing the monomer (0.0066 M EDOT) and poly(sodium 4-styrenesulfonate) (0.05 M NaPSS). Electrodeposition of PEDOT/PSS was carried out potentiostatically (0.95 V vs. $\mathrm{Ag} / \mathrm{AgCl}$ in $0.1 \mathrm{M} \mathrm{KCl}, \mathrm{t}=200 \mathrm{~s}, \mathrm{Q}=6,6 \mathrm{mC}$ ), under argon atmosphere, by the potentiostat-galvanostat AutoLab PGStat302 N system under GPES software control.

Characteristics of the electrodes were examined by measuring the cell EMF for aqueous solutions of given salts $\left(\mathrm{NaCl}, \mathrm{KCl}, \mathrm{LiNO}_{3}, \mathrm{NH}_{4} \mathrm{Cl}, \mathrm{CaCl}_{2}, \mathrm{MgCl}_{2}\right)$ and $\mathrm{HCl}$ (for chosen electrodes) over the concentration range of $10^{-7}-10^{-1}$ or $1 \mathrm{M}$. All measurements were carried out at room temperature (ca. $20^{\circ} \mathrm{C}$ ). The selectivity coefficients $(\log K)$ were determined by the Separate Solution Method (SSM) [36] according to the following formula using $0.1 \mathrm{M}$ solutions of the salts:

$\log K_{I J}^{p o t}=\frac{\left(E_{J}-E_{I}\right)}{S_{I}}+\log \left(a_{I}\right)-\frac{z_{I}}{z_{J}} \log \left(a_{J}\right)$

$E_{J}$-interfering ion potential; $E_{\Gamma}$ main ion potential; $S_{\Gamma}$ main ion characteristics slope; $a_{l}, z_{i}$-activity and charge of main ion; $a_{J}, z_{j}$-activity and charge of interfering ion.

The correlation between the potential and $\mathrm{pH}$ was tested for constant $\mathrm{NaCl}$ concentrations $\left(10^{-1}, 10^{-2}\right.$ and $\left.10^{-4} \mathrm{M}\right)$ and variable concentrations of $\mathrm{HCl}$ or $\mathrm{LiOH}$.

In order to determine the levels of sodium in the real-life sample, a solution comprising $\mathrm{KCl}$ (4.2 mM), $\mathrm{CaCl}_{2}$ (1.1 $\mathrm{mM})$, and $\mathrm{MgCl}_{2}(0.6 \mathrm{mM})$ was prepared, further referred to as "artificial plasma". Artificial plasma was used as background for characterization of the electrodes used for determination of sodium levels in real-life plasma samples. The activity of sodium ions in plasma was determined by direct measurement method.

\section{Examination of UV light effect on response of electrode containing biscrown ionophore 1}

The properties of $\mathbf{g c}^{\prime}$ type electrodes with compound $\mathbf{1}$ as an ionophore was tested. In next step the membranes of 
those electrodes were irradiated for $1 \mathrm{~h}$ with a lamp emitting light of $365 \mathrm{~nm}$ (power of $9 \mathrm{~W}$ ). Immediately after irradiation another series of measurements was performed. After $1 \mathrm{~h}$ and next after 1 day of electrodes conditioning the measurements were repeated.

Independently, the acetone solution of compound $\mathbf{1}$ was irradiated (UV, $365 \mathrm{~nm}, 9 \mathrm{~W}$ ). Immediately after the irradiation only a small amount of the trans-trans isomer was observed (TLC). Its content was estimated at approximately $5 \%$. ${ }^{1} \mathrm{H}$ NMR spectrum was also registered directly after irradiation of compound $\mathbf{1}$ in d-acetone. The content of particular isomers was estimated as: cis-cis isomer ca. $65 \%$, trans-cis isomer ca. $30 \%$, trans-trans isomer ca. $5 \%$ (Fig. 4).

\section{Determination of lipophilicity of the ionophores 1, 2 and 3}

Lipophilicity of new ionophores was determined by TLC [37] using reverse-phase chromatographic plates and ethanol-water 10:1 as the mobile phase. DOP, DOS, $o$ NPOE, and BBPA were used as the reference standards. Lipophilicity values calculated for the compounds $\mathbf{1}, \mathbf{2}$, and 3 were $\log \mathrm{P}_{\mathrm{TLC}}=12.0 \pm 0.3,13.1 \pm 0.2$, and $7.0 \pm 0.5$, respectively.

\section{Determination of the stability constant values and stoichiometry of complex of biscrown 1 with sodium iodide}

UV-Vis measurements were recorded in acetone using quartz cuvettes $(0.2 \mathrm{~cm})$. The spectral changes of ligand solution of defined concentration $\left(c_{\mathrm{L}}=1.12 \times 10^{-4} \mathrm{M}\right.$, $0.4 \mathrm{~mL}$ ), were recorded upon stepwise addition of $40 \mu \mathrm{L}$ of the salt solution (titration step) directly into the measurement cell (concentration of stock solution of the salt was $\left.8.17 \times 10^{-3} \mathrm{M}\right)$. Spectrophotometric titration was ended at concentration ratio $\mathrm{c}_{\mathrm{NaI}} / \mathrm{c}_{\mathrm{L}}=43.82$ (after addition of $240 \mu \mathrm{L}$ of stock solution of salt into measurement cell). On the basis of experimental data the stability constant values and stoichiometry of species were determined using the OPIUM software [38].

\section{Results and discussion}

\section{Synthesis}

The synthetic approach to novel ionophores is shown in Scheme 1.

Suitable bromo derivatives [8] were subjected to reaction with potassium salts of acids. Reactions were carried out in acetonitrile $(\mathrm{ACN})$ at $75{ }^{\circ} \mathrm{C}$. An analogous reaction with silver salt and a synthetic method featuring dodecylmethylmalonic acid dichloride and hydroxyl derivatives of alkoxyazobenzocrowns were also tested, but the best results were achieved using the method outlined in Scheme 1. The yield of the synthesis and isolation of biscrowns was about $40 \%$.

Equilibria between the two geometric isomers of azobenzocrown 3, i.e. trans and cis isomers and between the three isomers, i.e. the trans-trans, trans-cis and cis-cis isomers of bis(azobenzocrown)s $\mathbf{1}$ and $\mathbf{2}$, are observed in the solutions. In acetone solution of the ionophore $\mathbf{3}$ a typical for derivatives of 13-membered azobenzocrown ratio of trans to cis isomers being 6:4 ( ${ }^{1} \mathrm{H}$ NMR) was observed. In solutions of biscrowns $\mathbf{1}$ and $\mathbf{2}$ the trans-trans and trans-cis isomers were dominant representing in sum approximately $90 \%$ of total amount of the compounds. For instance, for acetone solution of biscrown 1 the content of trans-trans, trans-cis and cis-cis stereoisomers was estimated at 5.5:3.5:1 respectively ( ${ }^{1} \mathrm{H}$ NMR). Malonate bis(azobenzocrown)s are characterized by large differences in chromatographic properties (TLC,) of trans-trans and trans-cis isomers. The difference is particularly large for compound 2. On the basis of our many years, extensive experience with this type of compounds e.g. [4] we may conclude that this may indicate distinctly different complexation properties of these isomers in favor of the transtrans isomer. The trans-trans isomer should be capable of forming an intramolecular sandwich-type complex (Fig. 2) while the trans-cis isomer should rather form intermolecular complexes due to the poor complexation capabilities of the cis isomers of azobenzocrowns. This finds confirmation in our previous results as well in researches published by other authors $[1,12,39]$.

\section{The interaction of the ionophore 1 with sodium ions in acetone solution}

Comparison of ${ }^{1} \mathrm{H}$ NMR spectra of compound $\mathbf{1}$ (d-acetone) and the spectra of the same compound in the presence of sodium iodide revealed that the presence of sodium ions shifts the equilibrium towards the predominance of the trans-trans isomer (Fig. 3). Obtained results suggest, that

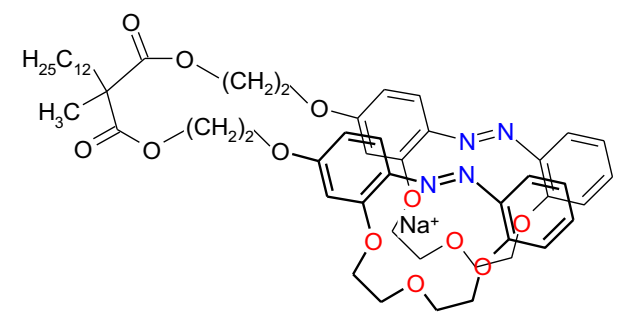

Fig. 2 Schematically, the probable structure of complex of biscrown 1 with sodium ion 


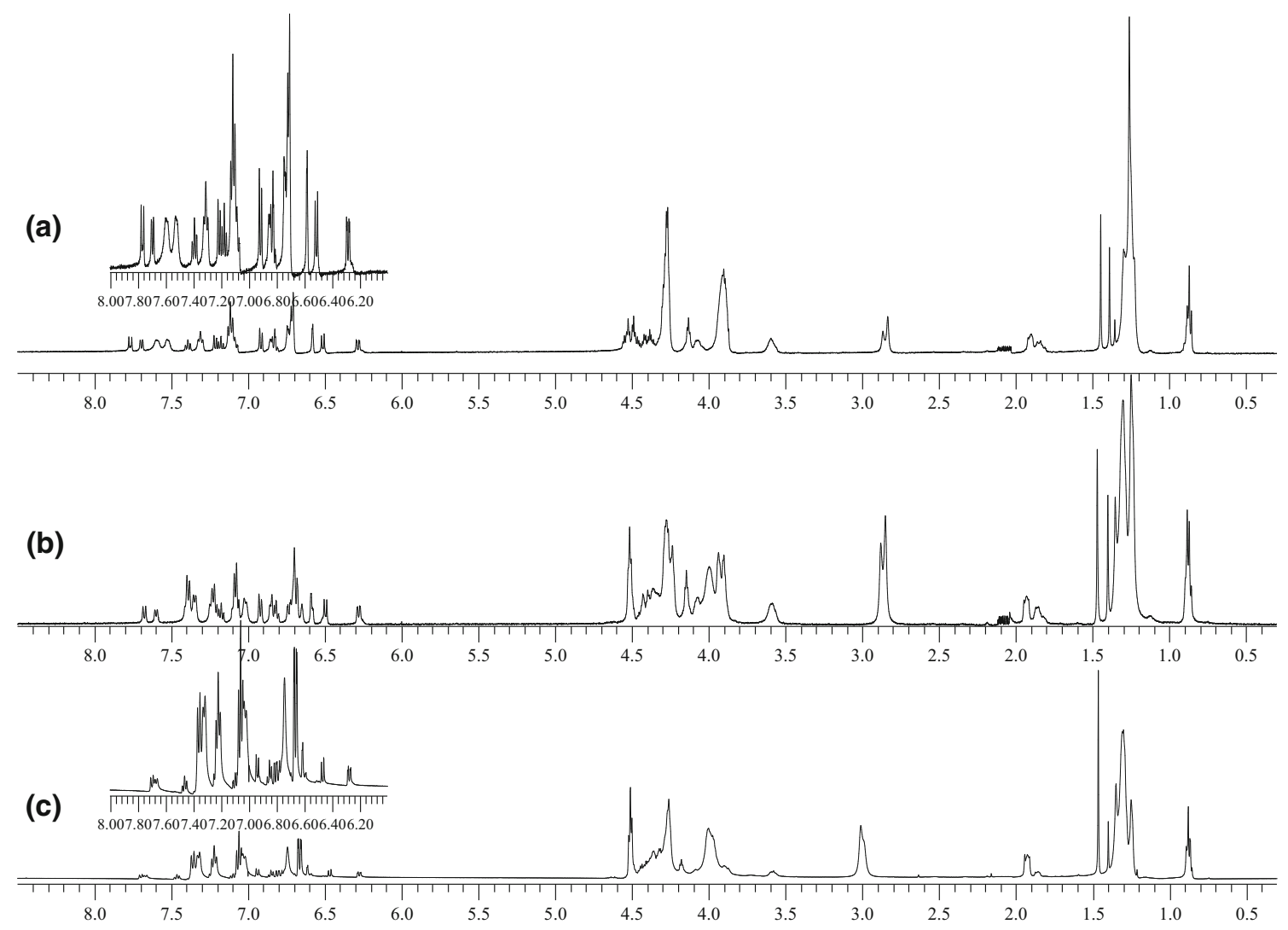

Fig. $3{ }^{1} \mathrm{H}$ NMR spectra of compound $\mathbf{1}$ in d-acetone: a without salt, $\mathbf{b}$ spectrum registered directly after addition of equimolar amount of NaI, c spectrum in the presence of the salt registered after several hours. (Acetone peaks removed for clarity)

formation of complex with sodium ions by trans-trans isomer is strongly preferred.

In ${ }^{1} \mathrm{H}$ NMR spectrum of bisazobenzocrown 1 (Fig. 3) three ranges can be distinguished:

(1) The first one is range from 0.8 to $2.0 \mathrm{ppm}$, which can be assigned to protons of aliphatic hydrocarbon groups not adjacent to oxygen atoms. In this range changes of singlets intensity at 1.45, 1.39 and $1.36 \mathrm{ppm}$ corresponding to trans-trans, trans-cis, and cis-cis isomers respectively, can be tracked. Those signals practically do not change their position in the presence of the sodium salt. Also, in the range of $1.80-1.95 \mathrm{ppm}$, where signal of $\mathrm{CH}_{2}$ dodecyl fragment is present changes of signal intensity and position depending on isomeric composition of biscrown can be seen. Shifts of this signal due to complexation is also not observed. For transtrans isomer shift of this signal is $1.90 \mathrm{ppm}$.

(2) The second range is $3.5-4.6 \mathrm{ppm}$ corresponding to protons bound with ether carbon atoms including both protons of macrocycle and protons ethylene moieties from ester part of the ligand. It is a complex system of partly overlapping signals. From this range it can be concluded about the participation of macrocycles with cis-azobenzene moiety, on the basis of signal integration at $3.6 \mathrm{ppm}$ corresponding to protons at "central" carbon atoms of macrocycle. One of the most important changes in this part of ${ }^{1} \mathrm{H}$ NMR spectra of the free ligand and its complex is a shift of signal (s) of four protons: $\mathrm{ArOCH}_{2}$-two from each macrocycle from 4.3 to $4.5 \mathrm{ppm}$ as a consequence of sodium ions complexation by trans-trans isomer.

(3) The third range is $6.2-7.8 \mathrm{ppm}$. A complicated system of multiplets corresponding to seven signals of trans-trans isomer, fourteen signals of trans-cis isomer, and seven signals of cis-cis isomer is here observed (in Fig. 3 they are hardly visible). The most readable is the c) spectrum (Fig. 3) for complex of trans-trans isomer of the biscrown with sodium iodide, where the trans-trans isomer is dominant ( $\sim 90 \%)$. However, a clear proton shielding with comparison to free ligand spectrum is here observed (Fig. 3a). The most characteristic is shift of protons from ortho position to azo group (from 7.5-7.7 to 7.3-7.4) indicative of the reduced electron-donor properties of azo group, taking probably part in sodium ions complexation. Similar changes were observed in the spectra of the complex of the parent, 
13-membered azobenzocrown acquired in $\mathrm{CDCl}_{3}$ [12].

Signals characteristic for cis-cis isomer are the most visible in ${ }^{1} \mathrm{H}$ NMR spectrum of biscrown irradiated with UV light (Fig. 4), where content of cis-cis isomer was estimated as $65 \%$.

Althought, changes in ${ }^{1} \mathrm{H}$ NMR spectra in the presence of salt are evident, chemical shifts of particular signals connected only with complexation process are not large enought for reliable determination of stoichiometry of formed complexes. This is why, interactions of compound 1 with sodium iodide were also tested using UV-Vis spectrophotometry. The presence of salt in ligand solution in acetone causes hyperchromic shift of ligand spectrum (Fig. 5). The system equilibrates at large molar excess of salt $\left(\mathrm{c}_{\mathrm{NaI}} / \mathrm{c}_{\mathrm{L}}=10\right)$. On the basis of analysis of experimental data the most probable binding model for $1-\mathrm{NaI}$ system is 1:1 stoichiometry (intramolecular sandwich complex, Fig. 2). The stability constant estimated for created species using OPIUM software is $\log K \sim 3.0$.

In the case of small macrocycles, and of lack of polarizing or ionizing moieties in azobenzocrown structure spectacular changes in UV-Vis spectra of azobenzocrown and their complexes of sandwich type are not seen (e.g. [3]).

\section{Membrane ion-selective electrodes}

We present the results of research for potentiometric ion selective membrane electrodes with three new sodium ionophores $\mathbf{1}, \mathbf{2}$ and $\mathbf{3}$. The use of these compounds, being capable of isomerization, as ionophores in ISEs, does not pose problems. Azobenzocrown compounds have been used as ionophores for two decades. Equilibrium is

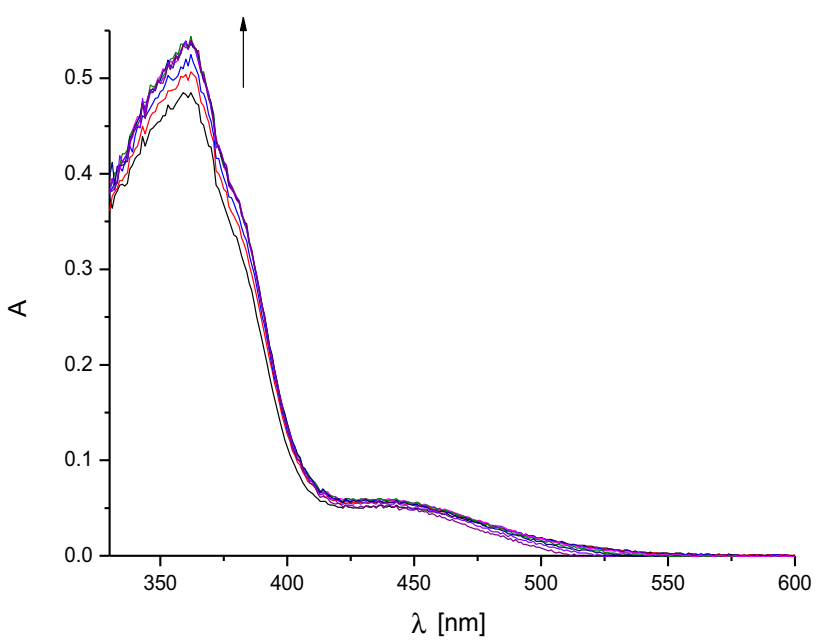

Fig. 5 Changes in UV-Vis spectrum of ligand $\mathbf{1}$ solution $\left(c_{\mathrm{L}}=1.12 \times 10^{-4} \mathrm{M}\right)$ in the presence of sodium iodide $\left(\mathrm{c}_{\mathrm{NaI}}\right.$ : $0-3.06 \times 10^{-3} \mathrm{M}$ ) in acetone

established between the isomers within the liquid membrane and thus the electrodes may operate correctly even when pure cis isomer is introduced. The trans isomer is predominant in the equilibrium in solution for 13-membered or larger macrocyclic azocompounds, whereas in the case of smaller azobenzocrowns, e.g. 10-membered, the $c$ is isomer is characterized by slightly higher stability than the trans isomer [40]. Upon the contact of the membrane with a solution containing the preferred ion, the equilibrium should be even more shifted towards the trans isomer (or trans-trans in case of bis(azobenzocrown)s). In addition, the access of light may be reduced during the measurements. The effect of light on the results of potentiometric studies was preliminary studied by means of measurements conducted in darkness. No significant differences in

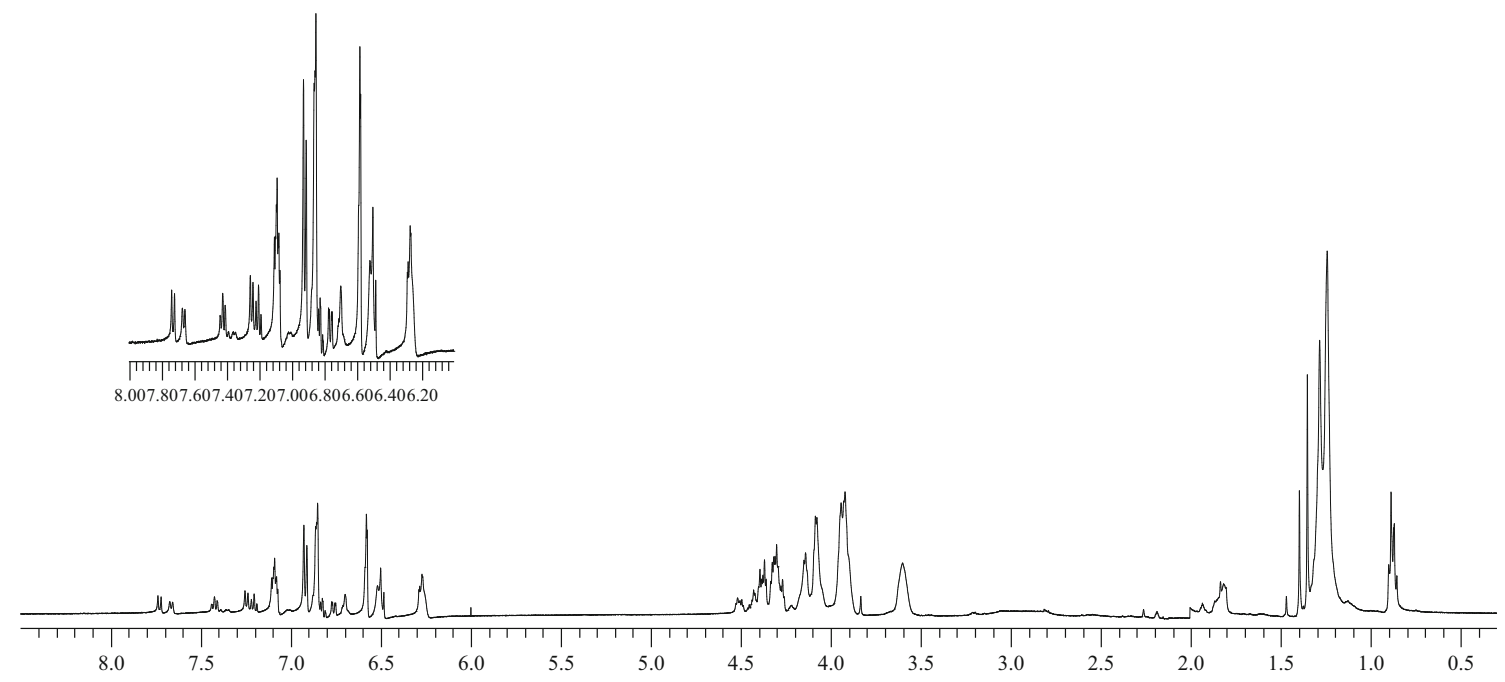

Fig. $4{ }^{1} \mathrm{H}$ NMR spectrum of compound 1 in d-acetone after irradiation with UV light $(365 \mathrm{~nm}$ ) for $1 \mathrm{~h}$. (Acetone and water peaks removed for clarity) 
electrode characteristics were observed. Only after irradiation of electrode membranes with a lamp emitting UV light with power of $9 \mathrm{~W}$ a temporary worsening of electrode characteristics was noticed. After 1 day of electrode conditioning in $\mathrm{NaCl}$ their parameters were similar to those before irradiation. Independently, the acetone solution of compound 1 was irradiated. Immediately after the irradiation only a small amount of the trans-trans isomer was observed (TLC). On the basis of spectrum registered in $\mathrm{d}$-acetone within $20 \mathrm{~min}$ after irradiation of compound $\mathbf{1}$ the presence of ca. $65 \%$ of cis-cis isomer, ca. $30 \%$ of transcis isomer, and ca. $5 \%$ of trans-trans isomer was claimed.

As in all the earlier studies on the use of azobenzocrowns and bis(azobenzocrown)s as ISE ionophores, also experiments reported herein required a relatively large, i.e. minimum $3 \%(\mathrm{w} / \mathrm{w})$ content of ionophore within the membrane for successful results. In our opinion, this is a general characteristic of azobenzocrown ionophores that form sandwich-type complexes with the preferred ions as well as of other crown derivatives forming sandwich-type complexes with the main ions eg. [35]. The optimum quantity of biscrown ionophores in membranes of all type of tested electrodes is $4-5 \%(\mathrm{w} / \mathrm{w})$. For the ionophore VI proposed amount in membrane is $6.5 \%(\mathrm{w} / \mathrm{w} /)$ [35].

$o$-NPOE was the typical plasticizer used in azobenzocrown-containing electrodes as it is considered good for sodium-selective electrodes. As shown in an example, also more lipophilic DOS may be used as the plasticizer for bis(azobenzocrown)-containing membranes. Ionophores $\mathbf{1}$, $\mathbf{2}$, and $\mathbf{3}$ were used in membranes of classic electrodes, membranes of miniature screen-printed planar graphite electrodes and membranes of glassy carbon-based electrodes. The latter type was studied to the greatest detail. Glassy carbon electrodes were also used for simultaneous comparative measurements using the commercial sodium ionophores: $\mathbf{X}$ (classification by Fluka)-p-tert-butylcalix[4]arene-tetraacetic acid tetraethyl ester and VIbis[(12-crown-4)methyl]dodecylmethylmalonate [21].

Figure 6 presents the characteristics of ionophore 2based graphite screen-printed electrodes, with the addition of carbon nanotubes in the membrane (s-p,n electrode) with respect to sodium and potassium ions.

Table 2 presents the selectivity coefficients determined by the SSM method $(0.1 \mathrm{M})$ for classic electrodes $(\mathbf{c})$ and two types of solid contact electrodes: graphite screenprinted (s-p and s-p,n) and glassy carbon electrodes (gc and $\left.\mathbf{g c}^{\prime}\right)$.

In Table 3 the changes in the properties of $\mathbf{g c}^{\prime}$ type electrodes with ionophore $\mathbf{1}$ due to irradiation with the UV lamp with power of $9 \mathrm{~W}$ and changes in the properties of exposure electrodes in time are shown.

Sodium/potassium selectivity coefficients were analyzed in particular. Electrodes with the tested biscrowns $\mathbf{1}$ and $\mathbf{2}$

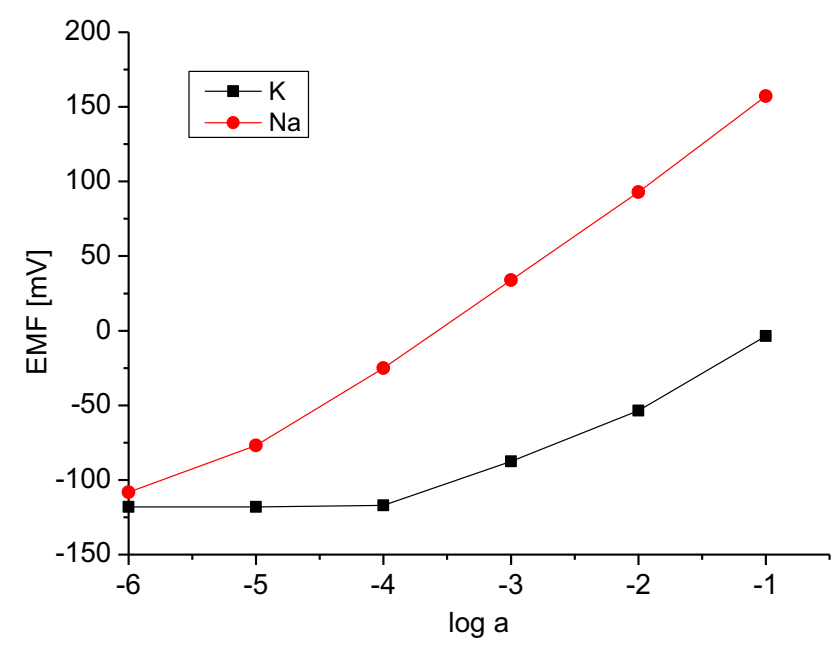

Fig. 6 The potentiometric response of the ionophore 2-based graphite screen-printed ISE (s-p,n type electrode) towards sodium and potassium ions

were found to have better selectivity coefficients $K_{N a, K}$ than the electrodes with the monocrown 3 . No significant difference in potentiometric responses of electrodes featuring ionophores $\mathbf{1}$ and $\mathbf{2}$ was observed; however, the best selectivity coefficient was achieved for the s-p,n electrode with compound 2 as the ionophore $(\log K=-2.6)$. In addition, compound $\mathbf{2}$ was obtained in higher yields than compound $\mathbf{1}$, however so far much more research was done with compound 1. No significant differences were also observed between the selectivities of the classic and solid contact electrodes; however, better (lower) limits of detection may be obtained for solid contact electrodes without internal electrolyte content. Particularly suitable from the standpoint of the stability of potential, detection limit and selectivity of biscrown-based electrodes was the addition of carbon nanotubes into the membrane cocktail deposited onto graphite screen-printed electrodes (s-p,n electrodes). The electro-conductive material was introduced directly into the membrane in a manner analogous to that proposed by Ivaska et al. [29]. In a case of glassy carbon electrodes (gc electrodes), the conductive PEDOT/PSS polymer blend was used as the intermediate layer between the membrane and glassy carbon. Preliminary studies, with the use of ISEs based on azobenzocrowns, on the introduction of the intermediate layer of the conductive polymer by electropolymerization were done ( $\mathbf{g c}^{\prime}$ electrodes). Obtained in this way electrodes revealed better LDL than electrodes gc. Selectivity did not change significantly. Electrodes s-p,n type and gc type have similar characteristics but only ge electrodes can be used for 3 weeks or more (in continuous conditioning in $\mathrm{NaCl}$ solution $\left(10^{-3} \mathrm{M}\right)$ ) without changes of properties (see Fig. 9). 
Table 2 Selectivity coefficients $^{\mathrm{a}}$ (SSM, $\left.0.1 \mathrm{M}\right)$ and potentiometric response characteristics of sodium selective electrodes using compounds 1, 2, 3 and commercial sodium ionophores: $\mathbf{V I}$ and $\mathbf{X}$

\begin{tabular}{llllllll}
\hline Electrode $^{\mathrm{a}}$ & $\mathrm{LDL}$ & $\mathrm{S}[\mathrm{mV} / \mathrm{dec}]$ & $\log K_{N a, K}$ & $\log K_{N a, N H 4}$ & $\log K_{N a, L i}$ & $\log K_{N a, C a}$ & $\log K_{N a, M g}$ \\
& {$[\operatorname{loga}]$} & & & & & \\
\hline 1c & -4.5 & 59.1 & -2.5 & -3.2 & -3.0 & -3.9 & -4.5 \\
1 s-p & -4.5 & 56.7 & -2.5 & -3.2 & -3.1 & -3.9 & -4.5 \\
1 s-p,n & -5.3 & 57.9 & -2.5 & -3.1 & -3.1 & -3.9 & -4.4 \\
1gc & -5.3 & 58.3 & -2.5 & -3.1 & -2.9 & -3.8 & 4.0 \\
1gc & -5.9 & 57.2 & -2.5 & -3.1 & -2.8 & -3.8 & 4.0 \\
1gc_DOS & -4.9 & 60.2 & -2.4 & -3.2 & -2.9 & -3.8 & -3.9 \\
2c & -4.5 & 58.9 & -2.5 & -3.2 & -3.1 & -3.9 & -4.6 \\
2 s-p,n & -5.3 & 60.0 & -2.6 & -3.2 & -3.0 & -4.1 & -4.5 \\
2gc & -5.3 & 60.9 & -2.5 & -2.9 & -2.9 & -4.0 & -4.3 \\
3c & -5.0 & 60.1 & -2.2 & -3.0 & -2.9 & -4.0 & -4.7 \\
3 s-p,n & -5.0 & 60.0 & -2.2 & -3.0 & -2.9 & -4.0 & -4.7 \\
3gc & -5.1 & 59.2 & -2.2 & -2.9 & -2.9 & -4.0 & -4.1 \\
VIgc & -5.0 & 51.0 & -2.0 & -3.5 & -3.3 & -3.8 & -5.0 \\
Xgc & -6.0 & 59.4 & -2.7 & -3.7 & -3.2 & -3.8 & -4.9 \\
0gc & -4.0 & 50.0 & 1.8 & 1.2 & -1.4 & -1.9 & -2.4 \\
\hline
\end{tabular}

Mean values are presented for three classic electrodes, six screen-printed electrodes and three glassy carbon electrodes. Standard deviations were lower than 0.1

${ }^{a}$ Results for electrodes featuring $o$-NPOE plasticizer and one run for electrodes featuring DOS plasticizer1gc_DOS

${ }^{\mathrm{b}}$ Electrode without ionophore

$\boldsymbol{C}$ classic electrode, $\boldsymbol{s}-\boldsymbol{p}$ screen-printed graphite electrode, $\boldsymbol{s}-\boldsymbol{p}, \boldsymbol{n}$ screen-printed graphite electrode with the addition of carbon nanotubes in the membrane, $\boldsymbol{g} \boldsymbol{c}, \boldsymbol{g} \boldsymbol{c}^{\prime}$ glassy carbon electrodes)

Table 3 Selectivity coefficients (SSM, 0.1 M) and potentiometric response characteristics of sodium selective electrodes using compounds $1-$ changes in the properties of electrodes due to membrane irradiation (UV, $9 \mathrm{~W}$ )

\begin{tabular}{llllllrr}
\hline Electrode & $\begin{array}{l}\mathrm{LDL} \\
{[\operatorname{loga}]}\end{array}$ & $\mathrm{S}[\mathrm{mV} / \mathrm{dec}]$ & $\log K_{N a, K}$ & $\log K_{N a, N H 4}$ & $\log K_{N a, L i}$ & $\log K_{N a, C a} \log K_{N a, M g}$ \\
\hline $\mathbf{1 g c}^{\prime}$ & -5.9 & 57.2 & -2.5 & -3.1 & -2.8 & -3.8 & 4.0 \\
$\mathbf{1 g c}^{\prime}(\mathrm{UV})$ shortly after exposure & -5.2 & 56.3 & -2.0 & -2.0 & -2.0 & -3.4 & -3.1 \\
$\mathbf{1 g c}^{\prime}(\mathrm{UV})$ after 1 h & -6.1 & 60.2 & -2.2 & -2.8 & -2.6 & -3.5 & -3.6 \\
$\mathbf{1 g c}^{\prime}(\mathrm{UV})$ after 20 h & -6.1 & 59.7 & -2.5 & -2.9 & -2.7 & -3.8 \\
\hline
\end{tabular}

$\mathbf{g c}^{\prime}$ - glassy carbon electrode, $o$-NPOE plasticizer (UV)—irradiated electrode

Direct measurements were used to compare the characteristics of an electrode with a membrane featuring biscrown 1 with the characteristics of electrodes with a membrane featuring sodium ionophore VI or sodium ionophore $\mathbf{X}$ (glassy carbon electrodes). The electrode featuring sodium ionophore $\mathbf{X}$ was found to have a slightly better $\mathrm{Na} / \mathrm{K}$ selectivity as compared to the electrode with ionophore 1 (ca. 0.2 unit). A better detection limit was also observed for the electrode featuring sodium ionophore $\mathbf{X}$. On the other hand, the electrodes with ionophore VI and membrane composition as proposed in the Fluka catalogue and literature [35] reveal worse properties than not only novel, reported here biscrowns but also monoazobenzocrown 3. Electrodes featuring the tested ionophores 1-3 are characterized by response times not longer than $10 \mathrm{~s}$ (Fig. 7).

ISEs with 13-membered azobenzocrowns, particularly azobenzocrowns substituted at position para relative to the azo group are more $\mathrm{pH}$-sensitive than ISEs featuring larger, 16-membered azobenzocrowns; however, they also meet the $\mathrm{pH}$-sensitivity criterion required in medical diagnostics. Typical selectivity coefficient $\log K_{N a H}$ for electrodes with other ester derivatives of azobenzocrowns was $1 \div 1.5$ [2]. However, electrodes with tested biscrowns turned to be less sensitive for $\mathrm{pH}$ than electrodes bearing other derivatives of azobenzo-13-crown-4. Typical selectivity coefficient $\log \mathrm{K}_{\mathrm{Na}, \mathrm{H}}$ for electrode with compound 1 is 0.5 . 


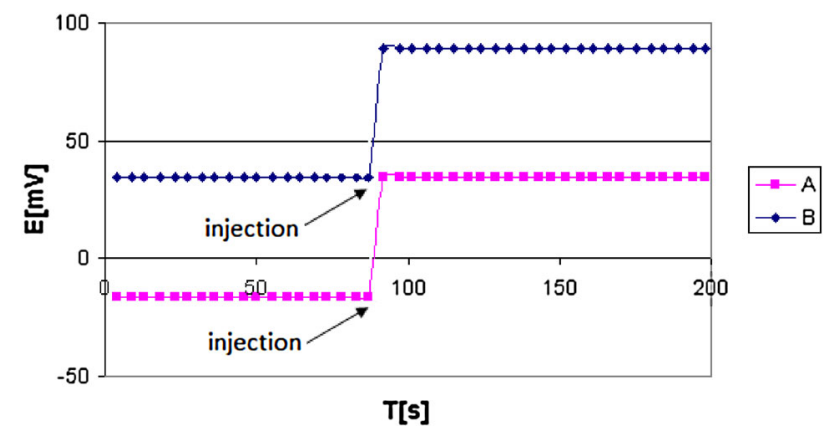

Fig. 7 Response time of the glassy carbon electrode with a membrane featuring ionophore 1 (o-NPOE). (a) $0.9 \mathrm{~mL}$ of $\mathrm{NaCl}$ solution $(0.1 \mathrm{M})$ was injected to $100 \mathrm{~mL}$ of $\mathrm{NaCl}$ solution $\left(10^{-4} \mathrm{M}\right)$. (b) $0.9 \mathrm{~mL}$ of $\mathrm{NaCl}$ solution $(1 \mathrm{M})$ was injected to $100 \mathrm{~mL}$ of $\mathrm{NaCl}$ solution $\left(10^{-3} \mathrm{M}\right)$

The effect of $\mathrm{pH}$ on responses of bis(azobenzocrown)featuring membrane electrodes was also studied at a constant concentration of sodium ions (Fig. 8). For $\mathrm{NaCl}$ concentration of $0.1 \mathrm{M}$, constant potentials were maintained in the $\mathrm{pH}$ range of 3-9 for electrodes featuring $o$ NPOE (ionophores 1 and 2) and 2-10 for the electrode featuring DOS (ionophore 1). At $\mathrm{NaCl}$ concentration of $10^{-4} \mathrm{M}$, the ranges were narrowed to $4-9,5-9$, and 5-10 for ionophore 2-o-NPOE, ionophore 1-o-NPOE and ionophore 1-DOS electrodes, respectively.

Lipophilicity of new ionophores $\mathbf{1 - 3}$ was determined as the factor influencing the electrode lifetime. Lipophilicity (TLC) of bis(azobenzocrowns) was in the range of $\log \mathrm{P}_{\mathrm{TLC}}=12-13$. Figure 9 presents the characteristics of glassy carbon electrode featuring compound $\mathbf{1}$ as a ionophore, recorded after the electrode had been conditioned for 3 weeks in $\mathrm{NaCl}$ solution $\left(10^{-3} \mathrm{M}\right)$. Of note is also the absence of the anionic effect at the activity of $1 \mathrm{M}$ which is

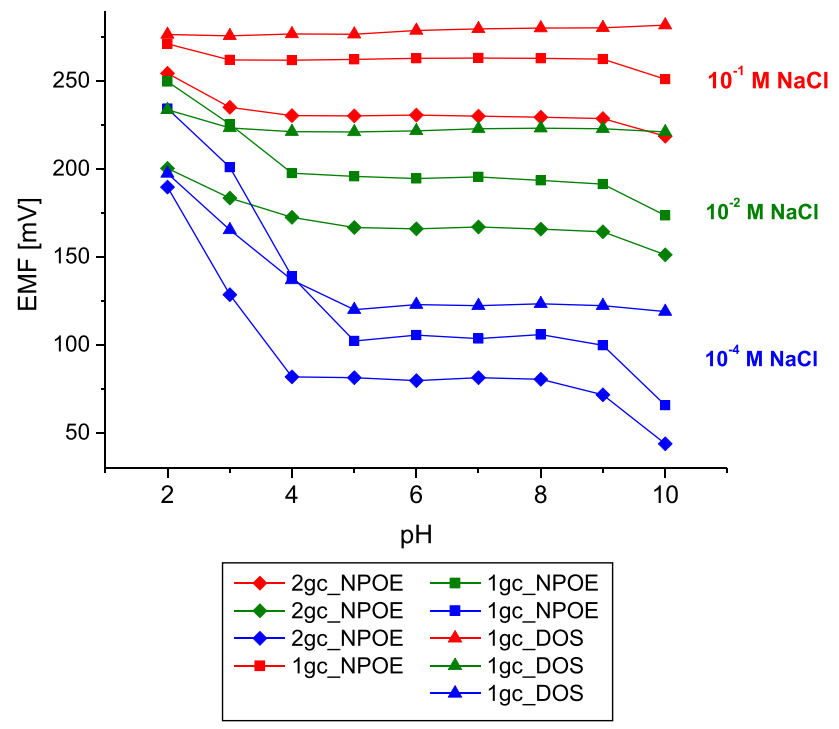

Fig. 8 The effect of $\mathrm{pH}$ on the responses of electrodes in the presence of sodium at different concentrations

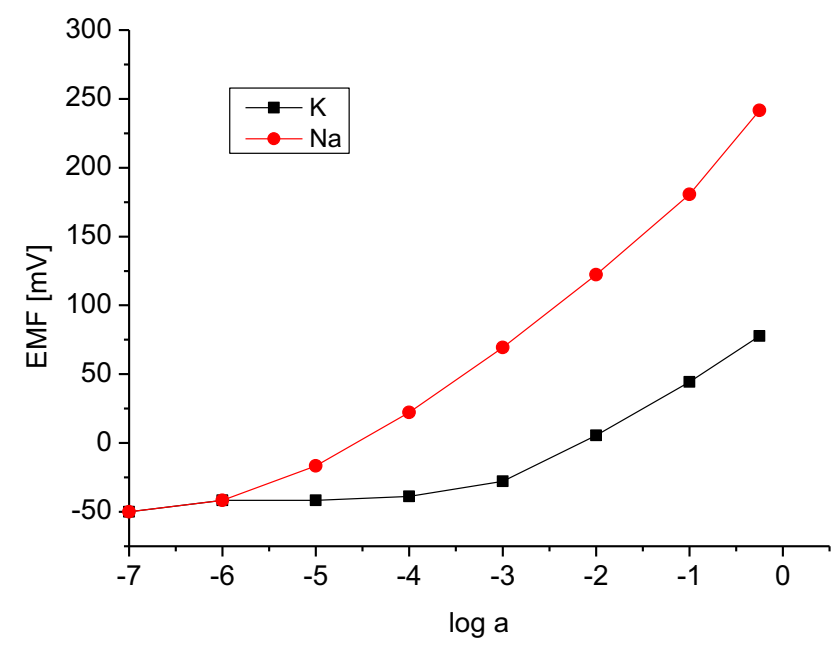

Fig. 9 Characteristics of the response of electrode 1gc to sodium and potassium ions after three-week conditioning in $\mathrm{NaCl}$ solution $\left(10^{-3} \mathrm{M}\right)$

also characteristic for electrodes featuring azobenzocrown ionophores. Those electrodes can be successfully used with activities higher than $0.1 \mathrm{M}$.

In such uses of colored azobenzocrowns, their color is useful only in the monitoring of potential washout of the ionophore from the electrode membrane. In case of the tested electrodes, no washout was observed even following prolonged conditioning.

Since we are interested in verification of the applicability of the synthesized ionophores in ISEs useful for clinical analysis, we evaluated the responses of the electrodes to variable concentrations of sodium ions in the presence of potassium, calcium and magnesium ions at concentrations corresponding to their respective blood plasma levels. Figure 10 presents the comparison of sodium response characteristics in the presence and in the absence of interfering ions. A near-Nernst response was recorded in the presence of interfering ions in the concentration range of above $10^{-4} \mathrm{M}$.

Glassy carbon electrodes featuring membranes with compounds $\mathbf{1}$ and $\mathbf{2}$ were used for determination of sodium levels in a real-life sample, i.e. human blood plasma. The obtained results were comparable to the result obtained in an independent measurement conducted in a clinical analytical laboratory (CAL, potentiometric method, Table 4). The most approximate result was obtained for the electrode featuring ionophore $\mathbf{2}$ and NPOE as plasticizer.

\section{Conclusions}

Three novel sodium ionophores suitable for ISEs to be used in clinical analysis were obtained, including two highly lipophilic $\quad\left(\log \mathrm{P}_{\mathrm{TLC}}=12-13\right) \quad$ bis(azobenzocrown)s- 


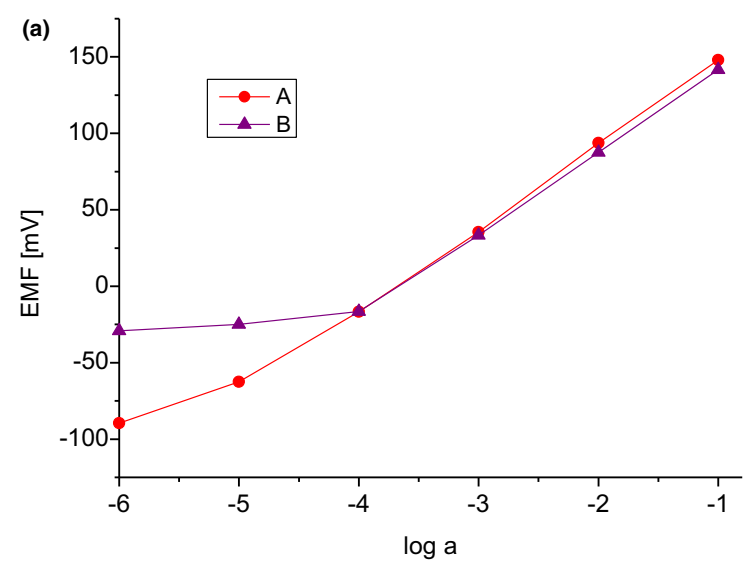

Fig. 10 Response curves for $\mathrm{Na}^{+}$obtained with ISEs based on ionophore 2. a graphite screen printed electrode (s-p,n). b glassy carbon electrode (gc). Curve $A$ indicates the response for $\mathrm{Na}^{+}$without

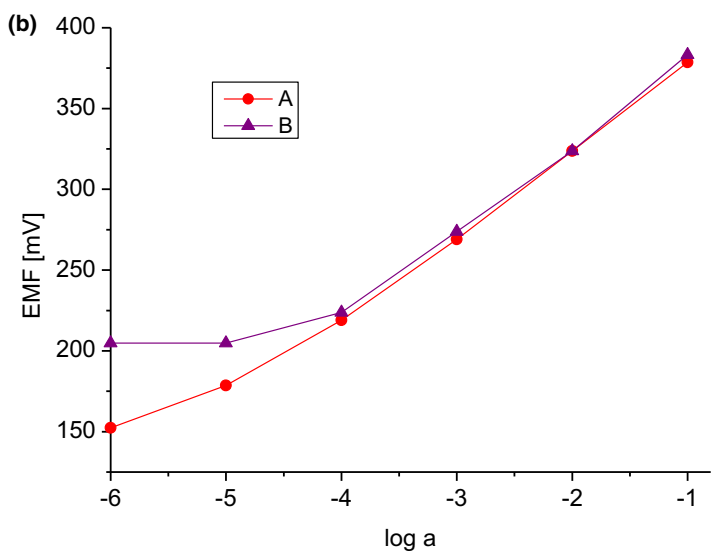

interfering ions. Curve $B$ indicates the response for $\mathrm{Na}^{+}$with interfering ions $\left(4.2 \mathrm{mM} \mathrm{K}^{+}, 1.1 \mathrm{mM} \mathrm{Ca}^{2+}, 0.6 \mathrm{mM} \mathrm{Mg}^{2+}\right.$ )

Table 4 Determination of blood plasma sodium levels using glassy carbon electrodes ( $n=3$ in any case) featuring bis(azobenzocrown)s as ionophores and the result of independent determination in a hospital clinical analytical laboratory (CAL)

\begin{tabular}{lllll}
\hline Electrode & 1gc_NPOE & 1gc_DOS & 2gc_NPOE & CAL \\
\hline Sodium concentration $(\mathrm{mmol})$ & 129.4 & 129.6 & 129.7 & 130.0 \\
\hline
\end{tabular}

diester derivatives of dodecylmethylmalonyl acid (compounds $\mathbf{1}$ and 2) and monoazobenzocrown ester 3. These ionophores proved to be very efficient in miniature solid contact electrodes, both graphite screen-printed and glassy carbon electrodes. Typical value of the sodium/potassium selectivity coefficient is $\log K_{N a, K}=-2.5$ (SSM, 0.1 M, with main ion conditioning). The electrodes featuring the novel ionophores also proved to be efficient in contact with human blood plasma.

A number of ionophores for sodium cations were earlier synthesized and practically used as the $\mathrm{Na}^{+}$sensing component for the ISEs. However, among commercial ionophores, only a calixarene derivative and a costly derivative of 16-crown-5 afforded $\mathrm{Na} / \mathrm{K}$ selectivities that were slightly better (Sodium ionophore $\mathbf{X}$ ) or better (Sodium ionophore IV) [21] than those of the lipophilic biscrowns $\mathbf{1}$ and 2 presented herein. Electrodes with tested biscrowns proved to be significantly better than the electrodes with structurally similar ionophore VI, both in terms of selectivity and the slope values of the electrode characteristics.

Acknowledgments The authors thank to Prof. Anna LisowskaOleksiak and MSc. Konrad Trzciński for help in performing electropolymerization. The authors acknowledge support from sources for science GUT Grants No. 031,402/T004 and No. 031466.

Open Access This article is distributed under the terms of the Creative Commons Attribution 4.0 International License (http://crea tivecommons.org/licenses/by/4.0/), which permits unrestricted use, distribution, and reproduction in any medium, provided you give appropriate credit to the original author(s) and the source, provide a link to the Creative Commons license, and indicate if changes were made.

\section{References}

1. Tahara, R., Morozumi, T., Nakamura, H., Shimomura, M.: Photoisomerisation of azobenzocrown ethers. Effect of complexation of alkaline earth metal ions. J. Phys. Chem. B. 101, 7736-7743 (1997)

2. Wagner-Wysiecka, E., Rzymowski, T., Szarmach, M., Fonari, M.S., Luboch, E.: Functionalized azobenzocrown ethers-the synthesis and ion binding properties. Sensor Actuat. B 177, 913-923 (2013)

3. Szarmach, M., Wagner-Wysiecka, E., Fonari, M.S., Luboch, E.: Bis(azobenzocrown ether)s-synthesis and ionophoric properties. Tetrahedron 68, 507-515 (2012)

4. Szarmach, M., Wagner-Wysiecka, E., Luboch, E.: Rearrangement of azoxybenzocrowns into chromophoric hydroxyazobenzocrowns and the use of hydroxyazobenzocrowns for the synthesis of ionophoric biscrown compounds. Tetrahedron $\mathbf{6 9}$, 10893-10905 (2013)

5. Luboch, E., Wagner-Wysiecka, E., Biernat, J.F.: Chromogenic azocrown ethers with peripheral alkyl, alkoxy, hydroxy or dimethylamino group. J. Supramol. Chem. 2, 279-291 (2002)

6. Luboch, E., Wagner-Wysiecka, E., Rzymowski, T.: 4-Hexylresorcinol-derived hydroxyazobenzocrowns as chromoionophores. Tetrahedron 65, 10671-10678 (2009)

7. Wagner-Wysiecka, E., Szarmach, M., Chojnacki, J., Luboch, E.: Cation sensing by diphenyl-azobenzocrowns. J. Photochem. Photobiol. A, submitted 
8. Luboch, E., Szarmach, M., Buczkowska, A., Wagner-Wysiecka, E., Kania, M., Danikiewicz, W.: Synthesis of thiol derivatives of azobenzocrown ethers. The preliminary studies on recognition of alkali metal ions by gold nanoparticles functionalized with azobenzocrown and lipoic acid. J. Incl. Phenom. Macrocycl. Chem. 83, 321-334 (2015)

9. Luboch, E., Wagner-Wysiecka, E., Poleska-Muchlado, Z., Kravtsov, VCh.: Synthesis and properties of azobenzocrown ethers with $\pi$-electron donor and $\pi$-electron acceptor group(s) on benzene rings. Tetrahedron 61, 10738-10747 (2005)

10. Cygan, A., Luboch, E., Biernat, J.F.: The effect of substituents in macrocyclic polyethers containing aromatic rings on ion-selective electrode properties. J. Incl. Phenom. 6, 215-220 (1988)

11. Luboch, E., Biernat, J.F., Simonow, YuA, Kravtsov, VCh., Bel'skii, V.K.: Structures of NaI complexes of 16-membered azoand azoxycrown ethers. Correlation of crystal structure and carrier-doped membrane electrode selectivity. Supramol. Chem. 11, 109-118 (1999)

12. Simonov, Yu.A., Luboch, E., Biernat, J.F., Bolotina, N.V., Zavodnik, V.E.: Inclusion compounds of NaI with 13-membered azo- and azoxycrown ethers. J. Incl. Phenom. 28, 17-32 (1997)

13. Suzuki, K., Sato, K., Hisamoto, H., Siswanta, D., Hayaski, K., Kasahara, N., Watanabe, K., Yamamoto, N., Sasakura, H.: Design and synthesis of sodium ion-selective ionophores based on 16-crown-5 derivatives for an ion-selective electrode. Anal. Chem. 68, 208-215 (1996)

14. Tamura, H., Kimura, K., Shono, T.: Coated wire sodium- and potassium-selective electrodes based on bis(crown ether) compounds. Anal. Chem. 54, 1224-1227 (1982)

15. Bourgoin, M., Wong, K.H., Hui, J.Y., Smid, J.: Interactions of macrobicyclic polyethers with ions and ion pairs of picrate salts. J. Am. Chem. Soc. 97, 3462-3467 (1975)

16. Fery-Forgues, S., Al-Ali, F.: Bis(azacrown ether) and bis(benzocrown ether) dyes: butterflies, tweezers and rods in cation binding. J. Photochem. Photobiol. C 5, 139-153 (2004)

17. Luboch, E., Cygan, A., Biernat, J.F.: Bis(benzocrown ether)s with polymethylene bridges and their application in ion-selective electrodes. Tetrahedron 47, 4101-4112 (1991)

18. Kleinpeter, E., Starke, I., Ströhl, D., Holdt, H.: NMR spectroscopic study of solution structure and complexational behaviour of bis-benzo crown ethers. J. Mol. Struct. 404, 273-290 (1997)

19. Wang, D., Sun, X., Hu, H., Liu, Y., Chen, B.: Bis crown ethersVI. The first single crystal structure of the complex of Schiff base type bis benzo-15-crown-5 and potassium picrate. Polyhedron $\mathbf{8}$, 2051-2056 (1989)

20. Lewenstam, A.: Routines and challenges in clinical application of electrochemical ion-sensors. Electroanalysis 26(6), 1171-1181 (2014)

21. www.sigmaaldrich.com/catalog

22. Bühlmann, P., Pretsch, E., Bakker, E.: Carrier-based ion-selective electrodes and bulk optodes. 2. Ionophores for potentiometric and optical sensors. Chem. Rev. 98, 1593-1687 (1998)

23. Yamamoto, H., Shinkai, S.: Molecular design of calix [4] arenebased sodium-selective electrodes which show remarkably high $10^{5.0}-10^{5.3}$ sodium/potassium selectivity. Chem. Lett. 6, 1115-1118 (1994)

24. Wojnarowicz, E., Deja, A., Pietrzak, A., Luboch, E., Biernat, J., Maj-Żurawska, M.: Azobenzocrown ethers as ionophores in ion selective membrane electrodes for potassium ion determination in blood serum. Mátrafüred 2014 International Conference on Electrochemical Sensors, Visegrád, Hungary, 15-20 June 2014
25. Bakker, E.: Determination of unbiased selectivity coefficients of neutral carrier-based cation-selective electrodes. Anal. Chem. 69, 1061-1069 (1997)

26. Ammann, D., Anker, P., Metzger, E., Oesch, U., Simon, W.: Ion measurements in physiology and medicine. In: Kessler, M., Harrison, D.K., Höper, J. (eds.) Proceedings of the International Symposium on the Theory and Application of Ion Selective Electrodes in Physiology and Medicine. Springer, Heidelberg (1985)

27. Steiner, R.A., Oehme, M., Ammann, D., Simon, W.: Neutral carrier sodium ion-selective microelectrodes for intracellular studies. Anal. Chem. 51, 351-353 (1979)

28. Anker, P., Jenny, H.-B., Wuthier, U., Asper, R., Ammann, D., Simon, W.: Potentiometry of $\mathrm{Na}^{+}$in undiluted serum and urine with use of an improved neutral carrier-based solvent polymeric membrane electrode. Clin. Chem. 29, 1508-1512 (1983)

29. Cadogan, A., Gao, Z., Lewenstam, A., Ivaska, A.: All-solid-state sodium-selective electrode based on a calixarene ionophore in a poly(vinyl chloride) membrane with a polypyrrole solid contact. Anal. Chem. 64, 2496-2501 (1992)

30. Bandodkar, A.J., Jia, W., Wang, J.: Tattoo-based wearable electrochemical devices: a review. Electroanalysis 27, 562-572 (2015)

31. Wang, X., Qin, Y., Meyerhoff, M.E.: Paper-based plasticizer-free sodium ion-selective sensor with camera phone as a detector. Chem. Commun. 51, 15176-15179 (2015)

32. Lisak, G., Arnebrant, T., Ruzgas, T., Bobacka, J.: Textile-based sampling for potentiometric determination of ions. Anal. Chim. Acta 877, 71-79 (2015)

33. Jasiński, A., Urbanowicz, M., Guziński, M., Bocheńska, M.: Potentiometric solid-contact multisensor system for simultaneous measurement of several ions. Electroanalysis 27, 745-751 (2015)

34. Cazalé, A., Sant, W., Ginot, F., Launay, J.-C., Savourey, G., Revol-Cavalier, F., Lagarde, M.J., Heinry, D., Launay, J., Temple-Boyer, P.: Physiological stress monitoring using sodium ion potentiometric microsensors for sweat analysis. Sens. Actuator B 225, 1-9 (2016)

35. Tamura, H., Kumani, K., Kimura, K., Shono, T.: Simultaneous determination of sodium and potassium in human urine or serum using coated-wire ion-selective electrodes based on bis(crown ether)s. Microchim. Acta 80, 287-296 (1983)

36. Umezawa, Y., Bühlmann, P., Umezawa, K., Tohda, K., Amemiya, S.: Potentiometric selectivity coefficients of ion-selective electrodes Part I. Inorganic cations. Pure Appl. Chem. 72, 1851-2082 (2000)

37. Dinten, O., Spichiger, U.E., Chaniotakis, N., Gehrig, P., Rusterholz, B., Morf, W.E., Simon, W.: Lifetime of neutral-carrierbased liquid membranes in aqueous samples and blood and the lipophilicity of membrane components. Anal. Chem. 63, 596-603 (1991)

38. Kyvala, M., Lukeš, I.: Program package "OPIUM" http://www. natur.cuni.cz/ kyvala/opium.html

39. Aoki, S., Shiga, M., Tazaki, M., Nakamura, H., Takagi, M., Ueno, K.: Ion-dipole association chromatography on ion-exchanger in non-aqueous media. Separation and characterization of crown ethers and related compounds. Chem. Lett. 11, 1583-1584 (1981)

40. Luboch, E., Wagner-Wysiecka, E., Kravtsov, VCh., Kessler, V.: Characterization of small azocrown ether stereoisomers. Pol. J. Chem. 77, 189-196 (2003) 